\title{
Rhinosporidosis of lacrimal sac: a case report
}

\section{Case report}

Rhinosporidiosis is a granulomatous disease that is caused by Rhinosporidium seeberi. ${ }^{1}$ Initially described by Seeber in 1900 in an individual from Argentina, ${ }^{2}$ rhinosporidiosis is endemic in South India, Sri Lanka, South America, and Africa. ${ }^{3,4}$ It usually affects the nasal mucosa and nasopharynx and rarely the conjunctiva, lacrimal sac, tonsils and skin. ${ }^{5}$ The clinical presentation is usually the pinkish polypoidal bleeding mass in the nasal cavity. This is a case study of an unusual presentation of isolated lacrimal sac rhinosporidiosis in a 12-year-old girl from a non endemic area.

A 12yrs old female presented to the Ophthalmology OPD with left infraorbital swelling for a period of 6years. She also complained of intermittent epiphora. External local examination revealed a diffuse, soft, and nontender swelling in the Left infraorbital region. Pressure over the mass produced a reddish mucopurulent discharge from the lower punctum. The overlying skin was normal. The vision and the extra ocular movements were normal. The patient was from North eastern part of India. A computed tomography scan of the par nasal sinuses revealed a hyper dense lesion in the subcutaneous plane of left infraorbital region. Fine needle aspiration report was no conclusive. The Gram stain of the mucopurulent discharge from the lower punctum collected by a sterile swab after applying pressure over the lesion revealed, thick walled sporangia, with endospores suggestive of Rhinosporidium seeberi (Figure 1).

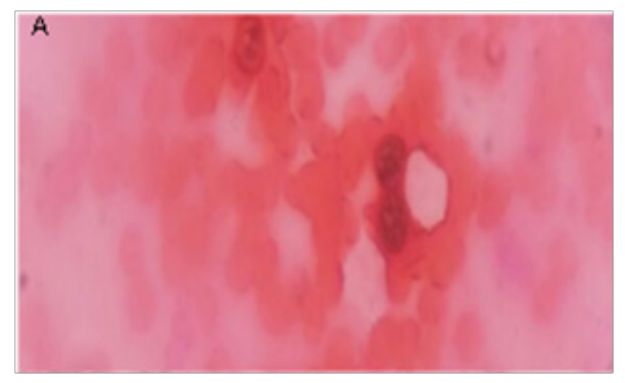

Figure I Gram stains showing thick walled sporangia with endospores.

The patient underwent a left infraorbital mass excision with dacryocystectomy under General Anaesthesia. Care was taken to avoid spilling of spores during complete removal of the mass. Extension of growth in nasolacrimal duct was also removed en bloc along with the sac. The nasolacrimal duct wall was curetted after removal of growth. Specimen was sent for fungal studies (Figure 2) and histopathology. The histopathological report was suggestive of rhinosporidiosis (Figure 3). The patient was kept on daily $100 \mathrm{mg}$ oral diaminodiphenylsulfone (DDS) (Daps one) for 3months and was instructed for regular follow up for detecting recurrence.

Rhinosporidiosis is presumably a waterborne disease, caused by Rhinosporidium seeberi. Though it occurs universally, $88 \%$ of cases are reported from India and Sri Lanka. Primary ocular rhinosporidiosis occurs in $10 \%$ of cases. The conjunctiva was the most common site of infection in $76(92.68 \%$ ) of the cases. The lacrimal sac was affected only in six $(7.32 \%)$ cases. $^{6}$ The pathway of transmission of rhinosporidiosis remains unclear. As the most affected sites are nose and eye, it has been suggested that infection occur while bathing in common pond

\author{
Volume 4 Issue 4 - 2017
}

\author{
Girish N, Prathima \\ Professor of Microbiology,Vydehi Institute of Medical Sciences \\ and Research Centre, India
}

Correspondence: Girish N, Professor of Microbiology,Vydehi Institute of Medical Sciences and Research Centre, Bangalore, India, Email girishdasanur@yahoo.co.in

Received: March 31, 2017| Published: April 12, 2017

i.e. water borne. It is true for our case also as there is history of taking bath in small pond. In this case, lacrimal sac alone was involved, it being a hollow protected viscous; the infection either would have reached the sac from nose or eye through lacrimal canaliculi without affecting the nose or conjunctiva. Epiphora is unusual in nasolacrimal rhinosporidiosis because the spread of infection is pericanalicular and perisaccular. ${ }^{7}$ However, our patient had complaints of intermittent epiphora with partially blocked nasolacrimal apparatus. It is essential to administer Daps one postoperatively to tackle the local sub epithelial and subcutaneous spread and to prevent recurrence. ${ }^{8}$ The role of Daps one in reducing the rate of postoperative recurrence is attributed to an arrest of maturation of the spores and an accentuated granulomatous response with fibrosis after Dapsone therapy. ${ }^{9}$ Though lacrimal sac rhinosporidiosis is rare, in all cases of infraorbital pathology, one need to keep a clinical diagnosis of lacrimal sac rhinosporidiosis in mind whenever patient belongs to tropical region.

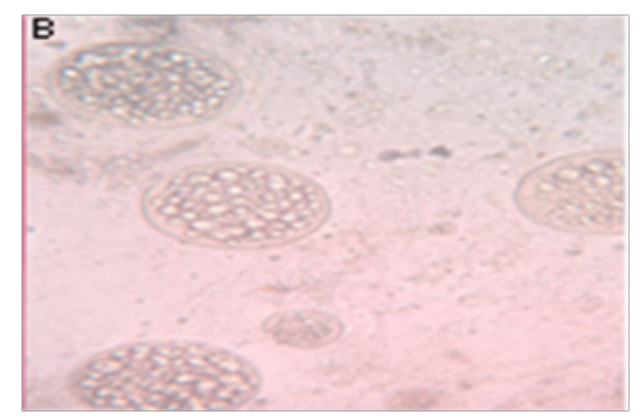

Figure $210 \% \mathrm{KOH}$ mount showing sporangia and endospores.

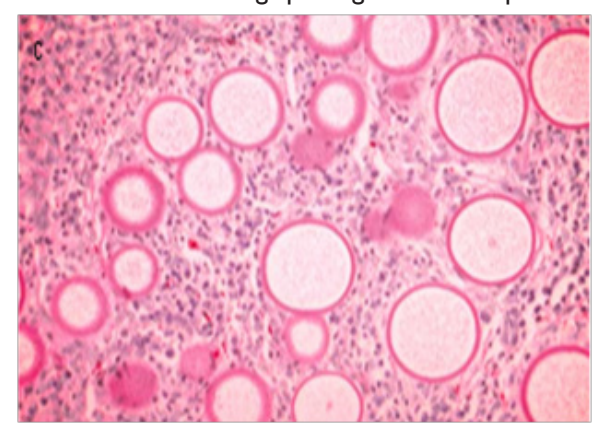

Figure $3 \mathrm{H}$ \& E stain showing thick walled sporangia of various sizes and endospores. 


\section{Acknowledgements}

None.

\section{Conflict of interest}

The author declares no conflict of interest.

\section{References}

1. Ashworth JH. On Rhinosporidium seeberi with special reference to its sporulation and affinities. Transactions of the Royal Society of Edinburgh. 1923;53(2):301-342.

2. Seeber GR. Un neuvo esporozoario parasito del hombre: dos casos encontrades en polipos nasales. Thesis Universidad Nacional de Buenos Aires; 1990.

3. Hospenthal DR. Uncommon Fungi and Prototheca. In: Mandell GL, et al. editors. Mandell, Douglas, and Bennett's Principles and Practice of
Infectious Diseases. 7th ed. Philadelphia, USA: Churchill Livingstone Elsevier; 2010. p. 3365-3376.

4. Kwon-Chung KJ, Bennett JE. Rhinosporidiosis. In: Medical Mycology, Philadelphia. Pa: Lea \& Febiger; 1992. p. 695-706.

5. Nerurkar NK, Bradoo RA, Joshi AA, et al. Lacrimal Sac rhinosporidiosis: A case report. Am J Otolaryngol. 2004;25(6):423-425.

6. Shrestha SP, Hennig A, Parija SC. Prevalence of rhinosporidiosis of the eye and its adnexa in Nepal. Am J Trop Med Hyg. 1998;59(2):231-234.

7. Nerurkar NK, Bradoo RA, Joshi AA, et al. Lacrimal Sac rhinosporidiosis: A case report. Am J Otolaryngol. 2004;25(6):423-425.

8. Nair K. Clinical trial of diaminodiphenylsulphone (DDS) in nasal and nasopharyngeal rhinosporidiosis. Laryngoscope. 1979;89(2):291-295.

9. Job A, Venkateswaran S, Mathan M, et al. Medical therapy of rhinosporidiosis with Dapsone. J Laryngol Otol. 1993;107(9):809-812. 